\title{
Hubungan Senam Nifas, Mobilisasi Dini, dan Tradisi Masa Nifas terhadap Proses Involusi pada Ibu Post Partum
}

\author{
Su'ada Roichana ${ }^{1}$, Yane Ari Pratiwi ${ }^{2}$ \\ ${ }^{1,2}$ Program Studi Kebidanan Program Sarjana Terapan Sekolah Tinggi Ilmu Kesehatan Indonesia Maju \\ Jln.Harapan Nomor 50, Lenteng Agung-Jakarta Selatan 12610, Indonesia \\ Telp: (021)78894045, Email: ${ }^{1}$ Roychanas@gmail.com ${ }^{2}$ Yane.silvano@yahoo.co.id
}

\begin{abstract}
Abstrak
Involusi uteri adalah masa kembalinya uterus kembali ke kondisi sebelum hamil. Salah satu faktor yang dapat mempengaruhi proses involusi uteri adalah dengan melakukan senam nifas, mobilisasi dini, serta menjalankan tradisi nifas yang baik menurut segi kesehatan. Penelitian ini bertujuan untuk mengetahui hubungan senam nifas, mobilisasi dini, dan tradisi masa nifas terhadap proses involusi uteri pada ibu postpartum di wilayah Kerja Puskesmas Slawi Kabupaten Tegal Tahun 2017. Penelitian ini bersifat deskriptif analitik dengan pendekatan crosssectional. Populasi dalam penelitian ini adalah seluruh ibu nifas di wilayah kerja Puskesmas Slawi Kabupaten Tegal bulan Oktober-Desember tahun 2017 sebanyak 163 ibu nifas. Teknik pengambilan sampel menggunakan accidental sampling sebanyak 57 ibu nifas. Hasil penelitian menunjukkan adanya hubungan antar variabel. Variabel senam nifas, mobilisasi dini, dan tradisi masa nifas terhadap variabel proses involusi uteri didapatkan hasil $\mathrm{P}=0,00$ berarti $\mathrm{P}<0,05$ yang artinya ada hubungan antara senam nifas, mobilisasi dini, dan tradisi masa nifas terhadap proses involusi uteri. Distribusi frekuensi proses involusi uteri menunjukkan bahwa dari 57 rsponden didapatkan 34 responden $(56,9 \%)$ mengalami involusi buruk, dan 23 responden $(40,4 \%)$ mengalami involusi baik. Oleh karena itu perlu adanya peningkatan penyuluhan dan pemberian informasi dari tenaga kesehatan serta dukungan keluarga dan suami kepada ibu nifas mengenai pentingnya melakukan senam nifas, mobilisasi dini dan menjalankan tradisi masa nifas yang tidak bertentangan dengan dunia kesehatan yang baik.
\end{abstract}

Kata kunci $\quad$ : Involusi uteri, Senam nifas, Mobilisasi dini, Tradisi masa nifas.

\begin{abstract}
Involution of the uterus is the return of the uterus back to the condition before pregnancy. One of the factors that can affect the process of uterine involution is by doing gymnastics gymnastics, early mobilization, and running a good childbirth tradition in terms of health. This study aims to determine the relationship between postnatal gymnastics, early mobilization, and puerperium tradition on the process of uterine involution in postpartum mothers in Slawi Regency Working Area of Tegal Regency in 2017. This research is analytical descriptive with cross sectional approach. The population in this research is all postpartum mother in Slawi Regency Public Health Center of Tegal Regency in October-December 2017 as many as 163 postpartum mothers. The sampling technique used accidental sampling of 57 postpartum mothers. The result of the research shows the relationship between variables. Variables of postpartum gymnastics, early mobilization, and postpartum tradition to variable process involution uteri got result $P=0,00$ mean $P<0,05$ meaning that there is relation between gymnastics gymnastics, early mobilization, and puerperium tradition to process involution uteri. The frequency distribution of uterine involution process shows that from 57 rsponden obtained 34 respondents (56,9\%) experiencing bad involution, and 23 respondents $(40,4 \%)$ have good involution. Therefore it is necessary to increase the counseling and provision of information from health workers as well as the support of family and husband to postpartum about the importance of doing gymnastics gymnastics, early mobilization and run the puerperium tradition that is not against the world of good health.
\end{abstract}

Keywords : uterine involution, postnatal gymnastics, early mobilization, puerperal tradition. 


\section{Pendahuluan}

Kematian ibu dan anak baru lahir mencerminkan kualitas pelayanan kesehatan dibidang obstetri yang belum baik. Angka kematian Ibu (AKI) atau Angka Kematipan Bayi (AKB) merupakan tolak ukur yang sensitif untuk melihat keberhasilan pelayanan kesehatan khususnya ibu dan anak. Menurut laporan dari World Health Organization (WHO), pada tahun 2014 Angka Kematian Ibu di dunia yaitu 289.000 jiwa. Amerika serikat 9300 jiwa, Afrika Utara 179.000 jiwa, dan Asia Tenggara 16.000 jiwa. $^{1}$

World Health Organization (WHO) menyatakan bahwa penyebab kejadian Angka Kematian Ibu di dunia menurut adalah perdarahan sebesar $27 \%$, infeksi sebesar $11 \%$, hipertensi dalam kehamilan sebesar $14 \%$, komplikasi Abortus sebesar 8\%, partus lama dan lainnya sebesar 9\%. Sedangkan penyebab Angka Kematian Ibu di Indonesia yaitu perdarahan menjadi angka tertinggi dibandingkan dengan penyebab - penyebab kematian maternal yang lain seperti keracunan dalam kehamilan, aborsi, dan infeksi. ${ }^{1}$

Angka Kematian Ibu juga menjadi salah satu indicator penting dalam menentukan derajat kesehatan masyarakat. AKI mengacu pada jumlah kematian ibu yang terkait dengan masa kehamilan, persalinan, dan nifas. Berdasarkan data yang diperoleh dari Puskesmas Slawi ada sebanyak 1.207 ibu nifas pada bulan januari 2016 sampai dengan bulan januari $2017 .^{2}$

Masa nifas adalah masa kembalinya uterus ke bentuk semula seperti sebelum hamil atau disebut juga dengan proses involusi uterus yang ditandai dengan penurunan tinggi fundus uterus. Involusi uterus pada ibu postpartum dipengaruhi oleh banyak faktor, salah satunya dengan aktifitas fisik yaitu senam nifas atau senam pasca melahirkan (dengan kondisi ibu sehat) yang bertujuan untuk mengurangi infeksi yang terjadi pada involusi uterus yang diakibatkan sisa darah yang tidak dikeluarkan, mengurangi resiko perdarahan abnormal serta untuk menghindari pembekuan darah yang menyumbat vena. Manfaat lain senam nifas adalah membantu memperbaiki sirkulasi darah, sikap tubuh dan punggung setelah melahirkan, memperbaiki tonus otot, pelvis dan peregangan otot abdomen serta memperbaiki otot panggul dan membantu ibu untuk lebih relaks dan segar pasca melahirkan. ${ }^{3}$

Dalam penelitian yang dilakukan oleh Ilma Saufika dan Machmudah tentang pengaruh senam nifas terhadap proses involusi uterus pada ibu nifas di RSUD Dr. H. Soewondo Kendal pada tahun 2015 diperoleh dari $68(77,8 \%)$ responden menunjukan bahwa sebagian besar responden melakukan senam nifas . Hasil analisis chi-square menunjukan nilai signifikansi $\mathrm{P}=0,000(\mathrm{sig}<0,05)$ yang artinya bahwa ada pengaruh antara senam nifas terhadap proses involusi uterus pada ibu postpartum. ${ }^{4}$

Salah satu aktifitas fisik yang dapat mempengaruhi proses involusi uterus selain senam nifas adalah dengan melakukan mobilisasi dini. Mobilisasi dini adalah gerakan gerakan awal yang dilakukan ibu post partum sejak hari pertama melahirkan (dilakukan oleh ibu nifas yang sehat). ${ }^{6}$ Mobilisasi dini juga merupakan salah satu kegiatan pemeliharaan kesehatan pada ibu post partum yang bertujuan untuk melancarkan aliran darah yang keluar dari uterus agar proses involusi uterus tidak terganggu atau mengalami sub involusi yaitu salah satunya dengan cara miring ke kiri dan ke kanan kemudian duduk dan berdiri serta latihan berjalan kaki, mengosongkan kandung kemih untuk memudahkan uterus untuk berinvolusi, melakukan pemijatan yang berguna untuk mengeluarkan bekuan darah yang menghalangi involusi uterus sehingga uterus dapat berkontraksi dengan baik, menyusui bayinya secara ondemand karena dengan sering menyusui bayi juga dapat membantu mempercepat proses involusi uterus. $^{5}$

Rista Apriyana melakukan penelitian tentang pengaruh mobilisasi dini terhadap penurunan tinggi fundus uteri pada ibu postpartum spontan di RSUD Tugurejo Semarang pada tahun 2015 dengan menerapkan uji Mann Whitney dan didapatkan hasil nilai $\mathrm{z}$ hitung adalah sebesar -4.373 dan nilai probabilitas atau p-value sebesar 0.000 , maka dapat disimpulkan bahwa $0.000<0.05$ yang artinya ada pengaruh antara mobilisasi dini terhadap penurunan tinggi fundus uteri pada ibu post partum spontan. ${ }^{6}$

Tradisi atau budaya bagi masyarakat adalah suatu hal yang penting, bahkan diantaranya di percaya dan menjadi pegangan 
hidup oleh masyarakat. Di beberapa wilayah di Indonesia, masih percaya pada mitos yang berkaitan dengan ibu dari masa hamil, melahirkan sampai masa nifas. Bagi masyarakat mitos sudah diyakini kebenarannya karena beberapa bukti yang terjadi. Masyarakat akan melakukan apa saja dengan harapan keselamatan pada ibu dan bayinya. ${ }^{7}$ Tradisi adalah segala sesuatu yang telah dilakukan untuk sejak lama dan menjadi bagian dari kehidupan suatu kelompok masyarakat, kebudayaan, waktu, atau agama yang sama. Tradisi masa nifas berarti segala sesuatu meliputi sikap dan perilaku sekelompok masyarakat yang menjadi kebiasaan turun temurun yang diwarisi dari masa lalu. Macammacam tradisi masa nifas dalam suku jawa secara turun temurun antara lain mengonsumsi jamu, pantangan makanan seperti ikan, daging, dan telur, dan pemakaian stagen. ${ }^{8}$

Perilaku positif yang masih dijalankan oleh sebagian besar ibu nifas dari suku jawa setelah melahirkan yaitu kebiasaan meminum jamu dengan tujuan agar ASI mereka lancar serta untuk kebugaran ibu. Jamu merupakan racikan tradisional dengan cara ditumbuk dan direbus airnya. Jamu ini dipercaya oleh sebagian masyarakat dapat memperlancar produksi ASI dan membantu proses involusi uteri karena bahan-bahan yang digunakan dalam pembuatan jamu meliputi bahan-bahan herbal seperti kunyit, asam jawa, rebusan daun katuk, lempuyang dan gula merah sehingga konsumsi jamu kerap menjadi pilihan ibu nifas karena dianggap lebih alami dan tidak ada efek samping. ${ }^{9}$

Menurut Murtiyanti, salah satu hambatan yang sering terjadi di masyarakat jawa adalah adanya pantang makan setelah melahirkan. Padahal setelah melahirkan seorang wanita memerlukan nutrisi yang cukup untuk memulihkan kembali organ reproduksinya. Mereka tidak menyadari bahwa tindakannya berpengaruh terhadap lambatnya pemulihan kesehatan kembali. Pantang makan merupakan warisan leluhur yang menurun dari generasi ke generasi dan tidak diketahui kapan dimulai serta apa sebabnya. ${ }^{11}$ Perilaku pantang makan adalah salah satu yang perlu dihindari demi pemulihan luka rahim dan pada saluran kemaluan. Banyak masyarakat dari suku jawa yang masih melakukan pantang makan setelah melahikan seperti pantang makan daging, ikan atau telur karena takut luka jahitan dan tali pusat bayi susah kering sehingga ibu mengalami keterlambatan dalam proses pemulihan, misalnya ibu kesulitan dalam berjalan karena masih merasakan sakit pada perutnya, ibu mengeluhkan produksi ASI nya sedikit dan talipusat bayi masih basah dan berbau. ${ }^{10}$

Menurut Dinas Kesehatan Provinsi Jawa Tengah penyebab kematian maternal paling banyak adalah pada waktu nifas sebesar $60,90 \%$, kemudian pada waktu hamil sebesar $26,33 \%$ dan pada waktu persalinan sebesar $12,76 \%$. Sementara berdasarkan kelompok umur kejadian kematian maternal terbanyak adalah pada usia produktif (20-34 tahun) sebesar 68,50\%, kemudian pada kelompok umur $\geq 35$ tahun sebesar $26,17 \%$ dan pada kelompok umur $\leq 20$ tahun sebesar $5,33 \%$. Penyebab kematian ibu disebabkan karena perdarahan sebanyak $21,14 \%$, hipertensi sebanyak 26,34\%, infeksi sebanyak 2,76\%, ganguuan system peredaran darah sebanyak $9,27 \%$ dan lain-lain sebanyak $40,49 \% .^{11}$

Berdasarkan data dari Dinas Kesehatan Kabupaten Tegal tahun 2014 jumlah AKI yaitu sebesar 173 per 100.000 kelahiran hidup (47 kematian ibu maternal dar 27.095 kelahiran hidup). Angka tersebut lebih tinggi bila dibandingkan dengan angka sebesar 146,6 per 100.000 kelahiran hidup (42 kematian ibu maternal dari 28.643 kelahiran hidup) pada tahun 2015. Menurut data dari Puskesmas Slawi Kabupaten Tegal tahun 2016 jumlah AKI mencapai 23 per 100.000 kelahiran hidup, mengalami peningkatan dibandingkan tahun 2016 sebanyak 16 per 100.000 kelahiran hidup. $^{2}$

Dari data di atas penyebab kematian maternal tidak terlepas dari kondisi ibu sendiri dan merupakan salah satu dari 4 kriteria "terlalu" yaitu terlalu tua pada saat melahirkan (>35 tahun), terlalu muda pada saat melahirkan $(<20$ tahun), terlalu banyak anak ( $>4$ anak), terlalu rapat jarak kelahiran/paritas $(<2$ tahun $){ }^{2}$

Hasil studi pendahuluan yang dilakukan di Puskesmas Slawi Kabupaten Tegal diperoleh data sebanyak $136 \mathrm{ibu}$ nifas pada bulan Oktober - Desember 2017. Sebanyak $76,2 \%$ ibu nifas mengalami involusi uterus, $33,6 \%$ ibu nifas mengalami sub involusi karena tidak melakukan senam nifas ataupun mobilisasi dini, dan $89,3 \%$ ibu nifas masih 
mengikuti tradisi masa nifas yang ada di daerah sekitarnya.

Dampak yang terlihat langsung pada saat dilakukan studi pendahuluan, bahwa sebagian dari ibu nifas enggan untuk mengikuti senam nifas yang diselenggarakan

di Puskesmas Slawi Kabupaten Tegal , sehingga menyebabkan angka sub involusi pada ibu nifas di wilayah tersebut meningkat. Sebagian ibu nifas masih berkenan untuk melakukan mobilisasi dini di rumahnya masing-masing namun tetap sebagian besar dari mereka memilih untuk tetap menjalankan tradisi masa nifas yang ada yang bertentangan dengan standar pelayanan kebidanan.

Tujuan penelitian ini adalah untuk mengetahui hubungan senam nifas, mobilisasi dini, dan tradisi masa nifas terhadap proses involusi uteri pada ibu post partum di wilayah kerja Puskesmas Slawi Kabupaten Tegal Tahun 2017.

\section{Metode}

Pada penelitian ini menggunakan metode deskriptif analitik yaitu suatu penelitian yang mencoba menggali bagaimana dan mengapa fenomena itu terjadi dan selanjutnya melakukan analisis dinamika kolerasi antar fenomena tersebut. ${ }^{12}$ Bersifat kuantitatif dengan pendakatan cross sectional atau potong lintang, yaitu suatu penelitian untuk mempelajari dinamika kolerasi antara faktor-faktor resiko atau variabel independen dengan efek atau variabel dependen yang di observasi atau pengumpulan datanya sekaligus pada suatu saat yang sama. ${ }^{5}$ Instrumen yang digunakan dalam penelitian ini adalah kuesioner, meliputi pernyataan terstruktur dan berkaitan dengan variabel yang akan diteliti.

Penelitian ini dilakukan di Puskesmas Slawi Kabupaten Tegal. Populasi dalam penelitian ini adalah 136 ibu nifas dan sampel dalam penelitian ini sebanyak 57 ibu nifas.

Teknik pengambilan sampel dalam penelitian ini menggunakan teknik Accidental Sampling yaitu tehnik pengambilan sample dengan siapa yang kebetulan dijumpai di tempat pada saat pelaksanaan penelitian.

Pengambilan sampel dimaksud untuk mengungkap fakta mengenai variabel yang diteliti dengan menggunakan metode yang tepat dan instrumen yang baku. Cara memperoleh data dikenal sebagai metode pengumpulan data dengan menggunakan teknik, prosedur serta alat yang dapat diandalkan karena baik buruknya suatu penelitian. Metode pengumpulan data dilakukan denagn cara membagikan kuesioner yang diberikan pada ibu nifas, setelah mendapatkan rekomendasi dan perijinan dari beberapa instansi terkait, peneliti kemudian melakukan penelitian pada subjek. Sebelum melakukan penelitian, peneliti akan memberitahukan maksud dan tujuan penelitian, peneliti akan memberi tahu maksud dan tujuan penelitian, bila responden bersedia, kemudian peneliti memandu responden secara individual dalam mengisi kuesioner, setelah itu kuesioner dikumpulkan kembali kemudian data yang terkumpul diolah atau di analisis.

Metode pengumpulan data dalam penelitian ini adalah kuesioner, yaitu sejumlah pertanyaan tertulis yang digunakan untuk memperoleh informasi dari responden dalam arti laporan dalam pribadinya, atau hal-hal yang ia ketahui. Dalam penelitan ini kuesioner yang digunakan adalah kuesioer terrtutup dengan maksud subyek yang dikenai kuesioner tinggal memilih jawaban yang tersedia.

Syarat sampel agar karakteristik sampel tersebut tidak menyimpang dari populasinya, perlu juga ditentukan kriteria inklusi maupun eksklusi. Kriteria inklusi adalah kriteria yang apabila terpenuhi dapat mengakibatkan calon objek menjadi objek penelitian, yaitu ibu nifas yang melakukan senam nifas, mobilisasi dini, dan tradisi masa nifas, dan ibu nifas yang berdomisili di wilayah kerja Puskesmas Slawi Kabupaten Tegal. Kriteria Non inklusi merupakan kriteria yang apabila terpenuhi dapat mengakibatkan calon objek menjadi valid, yaitu ibu nifas yang melakukan senam nifas, mobilisasi dini, dan tradisi masa nifas tetapi tidak hadir pada saat dilakukan penelitian. Kriteria eksklusi adalah kriteria diluar kriteria inklusi, yaitu ibu nifas yang tidak melakukan senam nifas, mobilisasi dini, dan tradisi masa nifas.

Data diolah dengan menggunakan komputerisasi. Data kemudian di input atau di entri. Editing, yaitu pemeriksaan kembali jawaban responden pada kuesioner yang mencangkup kelengkapan jawaban, keterbacaan tulisan, keseragaman ukuran, dan sebagianya sebelum diberi kode. Coding, yaitu 
kegiatan merubah data dalam bentuk huruf pada kuesioner tertutup atau semi tertutup menurut macamnya menjadi bentuk angka untuk pengolahan data komputer. Checking, yaitu melakukan pemeriksaan pada data yang akan dilakukan pengolahan, kegiatan ini dilakukan agar data yang diperoleh sesuai dengan data yang ada. Cleaning, yaitu kegiatan pembersihan data hasil entry data agar terhindar dari ketidaksesuaian dengan koding jawaban responden pada kuesioner. ${ }^{13}$

Sebelum instrumen atau alat ukur digunakan untuk penelitian maka dilakukan uji coba kuesioner terlebih dahulu yaitu dilakukan uji validitas dan reliabilitas. Analisa data dalam penelitian ini menggunakan bantuan komputerisasi SPSS 20.

Peneliti melakukan uji validitas dan

reliabilitas dengan menggunakan instrumen berupa kuisioner berjumlah 30 soal, membandingkan nilai $\mathrm{r}$ hitung (dalam output SPSS dinotasikan sebagai corrected item total) dengan $\mathrm{r}$ tebel menggunakan $\mathrm{df}=\mathrm{n}-2 \quad \mathrm{n}=$ jumlah responden), dengan derajat kemaknaan menggunakan Odds Ratio (OR) karena desain penelitiannya menggunakan rancangan Cross Sectional atau potong lintang. Untuk menguji reabilitas instrument, peneliti menggunakan Alpha Chronbach dari uji reabilitas ditanyakan realible bila nilai alpha $\geq \mathrm{r}$ tabel.

Dalam penelitian ini menggunakan uji Chi-Square karena variabel yang dihubungkan terdiri dari variabel independen (bebas) dalam bentuk kategorik dangan variabel dependen (terikat) dalam bentuk kategorik. Analisis ini bertujuan untuk mengetahui apakah benar ada hubungan antara variabel independen dengan variabel dependen, dalam hal ini uji yang cocok digunakan yaitu uji Chi-Square. Analisa data dalam penelitian ini menggunakan bantuan komputerisasi SPSS for windows versi 20.

Analisa univariat disajikan dalam bentuk tabel yang bertujuan untuk melihat distribusi frekuensi dari semua variabel yang diteliti. Analisa bivariat digunakan apabila ingin melihat hubungan antara variabel independen dan variabel dependen yang bertujuan untuk mengetahui apakah ada hubungan senam nifas, mobilisasi dini, dan tradisi masa nifas terhadap proses involusi uteri pada ibu post partum.. Melalui uji Chi-Square akan diperoleh nilai $\mathrm{P}$ value, dimana dalam penelitian ini digunakan tingkat kemaknaan sebesar 0,05. Penelitian antara dua variabel dikatakan bermakna jika mempunyai nilai $\mathrm{P}<0,05$ yang berarti $\mathrm{HO}$ ditolak dan Ha diterima. Dan dikatakan tidak bermakna jika mempunyai nilai $\mathrm{P}>0,05$ yang berarti Ho diterima dan Ha ditolak. ${ }^{14}$

Penyajian data yang dilakukan dalam penelitian ini adalah penyajian data dalam bentuk tabel untuk memberikan keterangan berbentuk angka. Penyajian data dalam bentuk teks dan narasi dilakukan untuk memberikan keterangan secara tulisan.

\section{Hasil}

\section{Analisis Univariat}

Analisis univariat yang akan dilakukan bertujuan untuk mengetahui distribusi frekuensi dari masing-masing variabel. Variabel yang diteliti berupa variabel independen yaitu senam nifas, mobilisasi dini, dan tradisi masa nifas, sedangkan variabel dependen yaitu proses involusi uteri.

Tabel 1. Distribusi Senam Nifas, Mobilisasi Dini, dan Tradisi Masa Nifas terhadap Proses Involusi Uteri pada ibu Post Partum

\begin{tabular}{lcc}
\hline \multicolumn{1}{c}{ Variabel } & $\begin{array}{c}\text { Frekuensi } \\
\text { (f) }\end{array}$ & $\begin{array}{c}\text { Presentase } \\
(\%)\end{array}$ \\
\hline Involusi uteri & & \\
Buruk & 34 & 59,6 \\
Baik & 23 & 40,4 \\
Senam nifas & 38 & \\
Tidak & 19 & 66,7 \\
Ya & & 33,3 \\
Mobilisasi dini & & \\
Tidak & 20 & 35,1 \\
Ya & 37 & 64,9 \\
Tradisi masa nifas & & \\
Kurang Baik & 34 & 59,6 \\
Baik & 23 & 40,4 \\
\hline
\end{tabular}

Berdasarkan tabel 1 distribusi frekuensi menunjukkan bahwa dari 57 responden ibu nifas didapatkan 34 responden $(56,9 \%)$ mengalami involusi uteri buruk dan 23 responden $(40,4 \%)$ mengalami involusi baik, 38 responden $(66,7 \%)$ tidak melakukan senam nifas dan 19 responden $(33,3 \%)$ melakukan senam nifas, 37 responden $(64,9 \%)$ melakukan mobilisasi dini dan 20 responden $(35,1 \%)$ tidak melakukan mobilisasi dini, 34 responden $(59,6 \%)$ masih menjalankan tradisi masa nifas yang kurang baik dan 23 responden $(40,4 \%)$ menjalankan tradisi masa nifas dengan baik. 
Tabel 2. Hubungan Senam Nifas, Mobilisasi Dini, dan Tradisi Masa Nifas terhadap Proses Involusi Uteri pada Ibu Post Partum

\begin{tabular}{lcccccccc}
\hline \multirow{2}{*}{ Variabel Penelitian } & \multicolumn{4}{c}{ Involusi Uteri } & \multicolumn{2}{c}{ Total } & \multirow{2}{*}{ OR } & P \\
& Buruk & \multicolumn{1}{c}{ Baik } & F & \% & F & \% & & Value \\
\hline Senam nifas & 31 & 81,6 & 7 & 18,4 & 38 & 100 & 23,619 & 0,000 \\
$\begin{array}{l}\text { Tidak } \\
\text { Ya }\end{array}$ & 3 & 15,8 & 16 & 84,2 & 19 & & & \\
$\begin{array}{l}\text { Mobilisasi dini } \\
\text { Tidak }\end{array}$ & 19 & 95,0 & 1 & 5,0 & 20 & & & \\
$\begin{array}{l}\text { Ya } \\
\text { Tradisi masa nifas }\end{array}$ & 15 & 40,5 & 22 & 59,5 & 37 & 100 & 27,867 & 0,000 \\
$\begin{array}{l}\text { Kurang baik } \\
\text { Baik }\end{array}$ & 33 & 97,1 & 1 & 2,9 & 34 & & & \\
\hline
\end{tabular}

Berdasarkan tabel 1 distribusi frekuensi menunjukkan bahwa dari 57 responden ibu nifas didapatkan 34 responden $(56,9 \%)$ mengalami involusi uteri buruk dan 23 responden $(40,4 \%)$ mengalami involusi baik, 38 responden $(66,7 \%)$ tidak melakukan senam nifas dan 19 responden $(33,3 \%)$ melakukan senam nifas, 37 responden $(64,9 \%)$ melakukan mobilisasi dini dan 20 responden $(35,1 \%)$ tidak melakukan mobilisasi dini, 34 responden $(59,6 \%)$ masih menjalankan tradisi masa nifas yang kurang baik dan 23 responden $(40,4 \%)$ menjalankan tradisi masa nifas dengan baik.

\section{Analisis Bivariat}

Analisis bivariat dilakukan untuk mengetahui apakah terdapat hubungan senam nifas, mobilisasi dini, dan tradisi masa nifas terhadap proses involusi uteri pada ibu post partum di wilayah kerja Puskesmas Slawi Kabupaten Tegal tahun 2017.

Berdasarkan tabel 2 diperoleh hasil variabel senam nifas, mobilisasi dini dan tradisi masa nifas dengan proses involusi uteri didapatkan nilai signifikan $\mathrm{P}$ Value $=0,000$ berarti $\mathrm{P}<0,05$ yang artinya ada hubungan senam nifas, mobilisasi dini dan tradisi masa nifas terhadap proses involusi uetri.

Variabel senam nifas didapatkan nilai $\mathrm{OR}=23,619$ yang berarti ibu nifas yang tidak melakukan senam nifas memiliki peluang 23 kali lebih besar mengalami involusi buruk dibanding dengan ibu nifas yang melakukan senam nifas, nilai $\mathrm{OR}=27,867$ pada variabel mobilisasi dini yang berarti ibu nifas yang melakukan mobilisasi dini memiliki peluang 27 kali lebih besar mengalami involusi baik dibanding dengan ibu nifas yang tidak melakukan mobilisasi dini. Sedangkan pada variabel tradisi masa nifas diperoleh hasil $\mathrm{OR}=$
27,600 yang artinya ibu nifas yang masih menjalankan tradisi masa nifas yang kurang baik memiliki peluang 27 kali lebih besar mengalami involusi buruk dibandingkan dengan ibu nifas yang menjalankan tradisi masa nifas yang baik.

\section{Pembahasan}

\section{Hubungan senam nifas terhadap proses involusi uteri pada ibu post partum}

Berdasarkan hasil penelitian senam nifas terhadap proses involusi uteri pada ibu postpartum di wilayah kerja puskesmas slawi kabupaten tegal, menunjukan bahwa dari 57 responden di wilayah kerja Puskesmas Slawi Kabupaten Tegal tahun 2017, didapatkan 31 responden $(81,6 \%)$ tidak melakukan senam nifas pada masa nifas sehingga mengalami proses involusi uteri yang buruk dan sebanyak 16 responden $(84,2 \%)$ melakukan senam nifas pada masa nifas sehingga mengalami proses involusi uteri yang baik.

Menurut Widyasih (2013) senam nifas adalah sederetan gerakan tubuh yang dilakukan untuk mempercepat pemlihan keadaan ibu setelah melahirkan yang dilakukan sejak hari pertama melahirkan setiap hari sampai hari ke sepuluh. Manfaat senam nifas ini yaitu membantu memperbaiki sirkulasi darah, memperbaiki sikap tubuh dan punggung setelah melahirkan, selain itu senam nifas juga memperbaiki otot abdomen setelah hamil dan memperkuat otot panggul. ${ }^{15}$

Sedangkan menurut Maryam (2013) Senam nifas adalah senam yang dilakukan oleh ibu setelah persalinan, setelah keadaan ibu normal (pulih kembali), atau latihan yang tepat untuk memulihkan kondisi tubuh ibu dan keadaan ibu secara fisiologis maupun 
psikologis. Senam nifas adalah latihan gerak yang dilakukan secepat mungkin setelah melahirkan, supaya otot-otot yang mengalami peregangan selama kehamilan dan persalinan dapat kembali kepada kondisi normal seperti semula. Senam nifas dapat dilakukan atau dimulai 6 jam setelah persalinan dan dalam pelaksanaannya harus dilakukan secara bertahap, sistematis, dan continue. ${ }^{16}$

Hal ini sesuai dengan penelitian yang dilakukan oleh Ilma Saufika dan Machmudah pada tahun 2015 diperoleh dari $68(77,8 \%)$ responden menunjukan bahwa sebagian besar responden melakukan senam nifas . Hasil analisis chi-square menunjukan nilai signifikansi $\mathrm{P}=0,000$ ( $\mathrm{sig}<0,05)$ berarti Ho ditolak atau gagal diterima yang menunjukan ada hubungan antara senam nifas terhadap proses involusi uterus. Hasil analisis regresi logistik menunjukan bahwa senam nifas terhadap proses involusi uterus adalah signifikan. $^{4}$

Menurut asumsi peneliti bahwa senam nifas terhadap proses involusi ibu nifas di wilayah kerja Puskesmas Slawi Kabupaten Tegal masih kurang baik, karena pemikiran masyarakat disana masih enggan mengikuti kegiatan senam nifas yang diselenggarakan pihak tenaga kesehatan dan lebih memilih bermalas-malasan pada masa nifas dengan tidak banyak melakukan banyak kegiatan sehingga sebenarnya dalam segi kesehatan akan membuat proses involusi lebih lama. Apabila petugas kesehatan memberikan penyuluhan mereka jarang menghadiri penyuluhan itu karena mereka menganggap mereka akan sembuh sendiri secara normal tanpa melakukan senam nifas. Kurangnya dukungan keluarga dan suami serta faktor lingkungan yang membuat senam nifas kurang di minati dan jarang dilakukan.

\section{Hubungan mobilisasi terhadap proses involusi uteri pada ibu post partum}

Berdasarkan hasil penelitian mobilisasi dini terhadap proses involusi uteri pada ibu postpartum di wilayah kerja Puskesmas Slawi Kabupaten Tegal, menunjukan bahwa dari 57 responden di wilayah kerja Puskesmas Slawi Kabupaten Tegal tahun 2017, didapatkan 19 responden $(95,0 \%)$ tidak melakukan mobilisasi dini pada masa nifas sehingga mengalami proses involusi uteri yang buruk dan sebanyak 22 responden $(59,5 \%)$ melakukan mobilisasi dini pada masa nifas sehingga mengalami proses involusi uteri yang baik.

Menurut Supardi S (2013) Mobilisasi dini adalah pergerakan yang dilakukan sedini mungkin ditempat tidur dengan melatih bagian-bagian tubuh untuk melakukan peregangan atau belajar berjalan. Mobilisasi dini atau ambulasi dini (early ambnulation) ialah kebijakan agar secepat mungkin bidan membimbing ibu postpartum bangun dari tenpat tidurnya dan membimbing ibu secepat mungkin untuk kembali berjalan. ${ }^{17}$

Sedangkan menurut Yuli Reni (2014) mobilisasi dini adalah kebijaksanaan untuk secepat mungkin membimbing pasien keluar dari tempat tidurnya dan membimbing untuk berjalan dalam 24-48 jam postpartum. ${ }^{18}$

Hal ini sesuai dengan penelitian yang dilakukan oleh Rista Apriyana (2015) tentang pengaruh mobilisasi dini terhadap penurunan tinggi fundus uterus pada ibu nifas, didapatkan hasil nilai $\mathrm{z}$ hitung sebesar -4.373 dan nilai probabilitas atau p-value sebesar 0,000 (< $0,05)$ yang dapat disimpulkan bahwa Ho ditolak atau gagal diterima yangberarti ada hubungan antara mobilisasi dini terhadap proses involusi uterus. Hasil analisis regresi logistik menunjukan bahwa mobilisasi dini terhadap proses involusi uterus adalah signifikan. ${ }^{6}$

Menurut asumsi peneliti bahwa mobilisasi dini terhadap proses involusi uteri pada ibu nifas di wilayah kerja Puskesmas Slawi Kabupaten Tegal baik, karena mayoritas masyarakat masih mau melakukan kegiatan mobilisasi dini sendiri di rumah walaupun tidak sedikit pula yang masih bermalasmalasan untuk melakukan mobilisasi dini mulai dari hari pertama melahirkan karena sebagian dari mereka menganggap dirinya belum mampu melaksanakan dan tubuhnya masih terasa lemah. Kurangnya dukungan keluarga dan suami serta faktor lingkungan yang membuat mobilisasi dini terkadang tidak dilakukan dari awal setelah melahirkan.

\section{Hubungan tradisi masa nifas terhadap proses involusi uteri pada ibu post partum}

Berdasarkan hasil penelitian tradisi masa nifas terhadap proses involusi uteri pada ibu postpartum diwilayah kerja Puskesmas Slawi Kabupaten Tegal, menunjukan bahwa dari 57 responden di wilayah kerja Puskesmas Slawi 
Kabupaten Tegal tahun 2017, didapatkan 33 responden $(97,1 \%)$ masih menjalankan tradisi masa nifas yang kurang baik pada masa nifas sehingga mengalami proses involusi uteri yang buruk dan sebanyak 22 responden (95,7\%) sudah menjalankan tradisi masa nifas yang baik pada masa nifas sehingga mengalami proses involusi uteri yang baik.

Menurut Maryni (2013) bahwa tradisi masa nifas adalah suatu tradisi atau budaya yang biasa dilakukan oleh ibu nifas yang turun temurun yang diwarisi dari masa lalu dan dipercaya serta diyakini kebenarannya dan masih tetap ada dan masih dilakukan sampai saat ini. ${ }^{19}$

Sedangkan tradisi masa nifas menurut Criswadani (2015) adalah kompleks yang mencakup pengetahuan, kepercayaan, kesenian, moral, hokum, dan adat istiadat, semua hasil karya, rasa, dan cipta masyarakat yang berfungsi sebagai tempat berlindung, kebutuhan makan dan minum, pakaian dan perhiasan, serta mempunyai kepribadian yaitu organisasi faktor-faktor biologis, psikologis dan sosialisasi yang mendasari perilaku individu dalam masa nifas. ${ }^{20}$

Hal ini sesuai dengan penelitian yang dilakukan oleh Handayani Sri (2013) tentang aspek sosial budaya pada kehamilan, persalinan, dan nifas di suku jawa terhadap proses involusi uterus, didapatkan hasil analisis chi-square yang menunjukkan nilai signifikasi $p$-value sebesar $0,000(<0,05)$ yang dapat disimpulkan bahwa Ho ditolak atau gagal diterima yang berarti ada hubungan antara tradisi masa nifas terhadap proses involusi uterus. Hasil analisis regresi logistik menunjukan bahwa tradisi masa nifas terhadap proses involusi uterus adalah signifikan. ${ }^{21}$

Menurut asumsi peneliti bahwa tradisi masa nifas terhadap proses involusi ibu nifas kurang baik, karena mayoritas masyarakat masih mempercayai budaya-budaya lokal setempat berkaitan tentang tradisi pada masa nifas seperti pantang makan, mengonsumsi jamu, dan pemakaian stagen, dan masih berpikiran bahwa dengan mengikuti tradisi masa nifas pada daerahnya akan sembuh masa nifasnya dengan sendirinya tanpa ada infeksi atau hambatan pada proses involusi uteri yang bisa saja muncul karena masih melakukan tradisi setempat yang bertentangan dengan standar pelayanan kebidanan. Kurangnya dukungan keluarga dan suami serta faktor lingkungan yang membuat tradisi masa nifas berjalan kurang baik.

\section{Kesimpulan}

Berdasarkan hasil penelitian tentang Hubungan Senam Nifas, Mobilisasi Dini, dan Tradisi Masa Nifas terhadap Proses Involusi Uteri pada Ibu Postpartum di Wilayah Kerja Puskesmas Slawi Kabupaten Tegal Tahu 2017 dapat disimpulkan bahwa distribusi frekuensi proses involusi uteri menunjukkan bahwa dari 57 responden didapatkan 34 responden $(56,9 \%)$ mengalami involusi uteri buruk dan 23 responden $(40,4 \%)$ mengalami involusi baik. Distribusi frekuensi senam nifas menunjukkan bahwa dari 57 responden didapatkan 38 responden $(66,7 \%)$ tidak melakukan senam nifas pada masa nifas dan 19 responden $(33,3 \%)$ melakukan senam nifas. Distribusi frekuensi mobilisasi dini menunjukkan bahwa dari 57 responden didapatkan 37 responden $(64,9 \%)$ melakukan mobilisasi dini dan 20 responden $(35,1 \%)$ tidak melakukan mobilisasi dini. Dan Distribusi frekuensi tradisi masa nifas menunjukkan bahwa dari 57 responden didapatkan 34 responden $(59,6 \%)$ tradisi masa nifasnya masih kurang baik dan 23 responden $(40,4 \%)$ tradisi masa nifasnya sudah baik.

Ada hubungan antara senam nifas terhadap proses involusi uteri, didapatkan nilai $\mathrm{P}=0,000$ berarti $\mathrm{P}<0,05$. Dari hasil analisis diperoleh nilai $\mathrm{OR}=23,619$ yang artinya $\mathrm{ibu}$ nifas yang tidak melakukan senam nifas memiliki peluang 23 kali lebih besar mengalami involusi buruk dibandingkan dengan ibu nifas yang melakukan senam nifas

Ada hubungan antara mobilisasi dini dengan proses involusi uteri, didapatkan nilai $\mathrm{P}$ $=0,000$ berarti $\mathrm{P}<0,05$. Dari hasil analisis diperoleh nilai $\mathrm{OR}=27,867$ yang artinya ibu nifas yang melakukan mobilisasi dini memiliki peluang 27 kali lebih besar mengalami involusi baik dibandingkan dengan ibu nifas yang tidak melakukan mobilisasi dini.

Ada hubungan antara tradisi masa nifas terhadap proses involusi uteri, didapatkan hasil nilai $\mathrm{P}=0,000$ berarti $\mathrm{P}<0,05$. Dari hasil analisis diperoleh nilai $\mathrm{OR}=27,600$ yang artinya ibu nifas dengan tradisi masa nifas yang kurang baik memiliki peluang 23 kali lebih besar mengalami involusi buruk dibandingkan dengan ibu nifas dengan tradisi masa nifas yang baik. 
Saran

Diharapkan Puskesmas Slawi Kabupaten Tegal Perlu diadakannya penyuluhan dan pemberian informasi yang menyeluruh kepada ibu nifas mengenai pentingnya melakukan senam nifas, mobilisasi dini dan menjalankan tradisi masa nifas yang tidak bertentangan dengan dunia kesehatan yang baik. Bagi ibu nifas perlu lebih memperhatikan informasi dari tenaga kesehatan setempat mengenai pentingnya melakukan senam nifas, mobilisasi dini dan tidak melakukan kebiasaan atau tradisi pada masa nifas yang dapat menghambat proses involusi uteri. Bagi Institusi Pendidikan dapat memperkaya ilmu dan menambah wawasan bagi profesi kebidanan dalam hal kasus sub involusi pada ibu nifas. Bagi penelitian selanjutnya diharapkan dapat mengembangkan ilmu atau gagasan dari teori-teori terbaru. Dan disarankan untuk melakukan penelitian dengan populasi yang lebih luas, serta lebih memperhatikan faktor-faktor lain yang diduga turut berperan dalam memberikan pengaruh atau membuat prediksi terhadap proses involusi uteri pada ibu nifas.

\section{Daftar Pustaka}

1. Depkes RI. Profil Kesehatan Indonesia 2015. Jakarta: Kementerian Kesehatan RI; 2015.

2. Dinkes Kab. Tegal. Profil Kesehatan Kabupaten Tegal tahun 2015. Tegal: Dinkes Kab.Tegal; 2015.

3. Permata D. Manfaat Senam Nifas Pasca Persalinan. Jakarta: Trans Info Media; 2013.

4. Saufika I dan Machmudah. Pengaruh Senam Nifas terhadap Proses Involusi Uterus pada Ibu Post Partum di RSUD. Dr. H. Soewondo Kendal. Jurnal Kebidanan. STIKes Telogorejo Semarang; 2015.3 (7)

5. Notoatmodjo S. Metodologi Penelitian Ilmu Kesehatan. Jakarta: Rineka Cipta; 2012.

6. Apriyana R. Pengaruh mobilisasi dini terhadap penurunan tinggi fundus uteri pada ibu postpartum spontan di RSUD Tugurejo Semarang.(Skripsi).STIKes Widya Husada Semarang; 2015.

7. Yulianti L. Gambaran Perawatan Ibu Nifas di Wilayah Kecamatan Miri Sragen. Jurnal Kesehatan. UMS Surakarta; 2014.7 (4)

8. Susila dan Suyanto. Metode Penelitian Epidemiologi. Yogyakarta: Bursa lmu; 2014.

9. Rasyi V. 30 Tanaman Herbal Untuk Pengobatan Tradisional. Yogyakarta: Sakti; 2013.

10. Murtiyanti dan Wiwik. Hubungan Pengetahuan dan Sikap Ibu tentang
Berpantang Makan pada Masa Nifas di Puskesmas Getasan Semarang. Jurnal Kebidanan. Akbid Ngudi Waluyo; 2013. 1 (13)

11. Dinkes Jateng. Profil Kesehatan Provinsi Jawa Tengah tahun 2015. Semarang: Dinkes Jateng; 2015

12. Sulistyaningsih. Metodologi Penelitian Kebidanan Kuantitaif-Kualitatif. Yogyakarta: Graha Ilmu; 2012.

13. Rustika dan Sudibyo S. Metodologi Riset Keperawatan. Jakarta: CV Trans Info Media; 2013.

14. Sofiyan S. Statistika Deskriptif untuk Penelitian. Jakarta: Rajawali Pers; 2014.

15. Adkon dan Riduan. Rumus dan Data dalam Analisis Statistika. Bandung: Alfabeta; 2013.

16. Widyasih dan Anita. Perawatan Masa Nifas. Yogyakarta: Graha Ilmu;2013.

17. Maryam K. Asuhan Kebidanan Masa Nifas. Jakarta: Salemba Medika; 2013.

18. Supardi S. Faktor-Faktor Yang Berhubungan Dengan Kejadian Perdarahan Postpartum. Jakarta: Salemba Medika;2012.

19. Yuli R. Buku Ajar Asuhan Kebidanan Masa Nifas Dan Menyusui. Jakarta: CV.Trans Info Media;2013.

20. Manga dan Maryni. Ilmu Sosial Budaya Dasar Kebidanan. Jakarta: Salemba Pustaka; 2013

21. Chriswardani. Faktor Sosial Budaya Dalam Praktik Kebidanan. Jurnal Promosi Kesehatan Indonesia. Jakarta; 2015. 1 (17)

22. Handayani S. Aspek Sosial Budaya pada Kehamilan, Persalinan Dan Nifas di Suku Jawa terhadap Proses Involusi Uterus. Jurnal Ilmiah Rekam Medis dan Informatika. STIKes Aisiyah Surakarta; 2013.4 (8)

23. Rahmad. Pemberian ASI dan MPASI terhadap pertumbuhan bayi usia 6-24 bulan. Jurnal Kedokteran. Poltekes Kemenkes RI Aceh; 2016. 1(17) 